\title{
Renin-angiotensin blockade is associated with increased mortality after vascular surgery
}

\section{L'inhibition du système rénine-angiotensine est lié à une augmentation de la mortalité suite à une chirurgie vasculaire}

\author{
Craig J. Railton, MD, PhD · Jacob Wolpin, PhD • \\ Jenny Lam-McCulloch, MSc $\cdot$ Susan E. Belo, MD, PhD
}

Received: 17 August 2009/Accepted: 10 May 2010/Published online: 4 June 2010

(C) Canadian Anesthesiologists' Society 2010

\begin{abstract}
Purpose The outcome of patients with preoperative renin-angiotensin system (RAS) blockade, achieved either by angiotensin converting enzyme inhibitors or angiotensin receptor blocking agents, was assessed using 30-day mortality as a primary end point.

Methods An observational cohort study of 883 consecutive patients undergoing elective open abdominal aortic aneurysm repair (AAA) was undertaken and analyzed using a propensity score matched study. The data collected included medical history, anesthetic techniques, and postoperative outcomes. Logistic regression analysis identified predictors of RAS blockade: hypertension, stroke, congestive heart failure, diabetes, and heart disease. A propensity score for RAS blockade was calculated for each subject using several factors: age, sex, serum creatinine, hypertension, heart disease, congestive heart failure, stroke, diabetes, and exposure to cardiovascular medications. Subjects and controls were matched using the calculated propensity score.
\end{abstract}

This article is accompanied by an editorial. Please see Can J Anesth 2010; 57(8).

C. J. Railton, MD, PhD ( $\square)$

Department of Anesthesia and Perioperative Medicine,

Rm. D2-315, London Health Sciences Centre, Victoria Campus, 800 Commissioners Road East, London, ON N6A 4G5, Canada e-mail: Craig.Railton@1hsc.on.ca

J. Wolpin, $\mathrm{PhD}$

Department of Clinical Pharmacology and Toxicology, Hospital for Sick Children, Toronto, ON, Canada

J. Lam-McCulloch, MSc - S. E. Belo, MD, PhD

Department of Anesthesia, Sunnybrook Health Sciences Centre,

Toronto, ON, Canada
Results The overall 30-day mortality rate was 3.5\% (31/883 patients). The crude mortality rate in RAS blocked patients was $5.8 \%(21 / 359)$ vs $1.9 \%$ (10/524) in unexposed patients (odds ratio 3.2, with 95\% confidence intervals [CI ${ }_{95}$ ] 1.5-6.7; $\left.P<0.001\right)$. Analysis of 261 propensity score matched pairs showed a 30-day mortality rate of $6.1 \%(16 / 261)$ in the RAS blocked group vs $1.5 \%$ (4/261) in unblocked patients $(P=0.008)$. The estimated odds ratio for 30-day mortality associated with RAS blockade was 5.0 (CI $I_{95}$ 1.4-27).

Conclusions Examination of 883 cases of AAA repair showed increased mortality associated with preoperative RAS blockade. A better understanding of perioperative pharmacology and physiology of RAS blockade is needed as well as future studies to identify causality.

\section{Résumé}

Objectif Le devenir des patients prenant, en préopératoire, des inhibiteurs du système rénine-angiotensine (SRA) (inhibiteurs de l'enzyme de conversion de l'angiotensine ou antagonistes du récepteur de l'angiotensine) a été évalué en utilisant le taux de mortalité à 30 jours comme critère d'évaluation principal.

Méthodes Une étude observationnelle menée auprès d'une cohorte de 883 patients consécutifs subissant une chirurgie ouverte programmée pour un anévrisme de l'aorte abdominale (AAA) a été entreprise et analysée à l'aide d'une analyse d'appariement par scores de propension. Les données recueillies incluaient les antécédents médicaux, les techniques d'anesthésie et les résultats postopératoires. L'analyse de régression logistique a permis d'identifier des variables prédisant la prise d'inhibiteurs du SRA: l'hypertension, les accidents vasculaires cérébraux, l'insuffisance cardiaque congestive, le diabète et les cardiopathies. Un score de propension pour la prise 
d'inhibiteurs du SRA a été calculé pour chaque sujet en tenant compte de plusieurs facteurs: l'âge, le sexe, la créatininémie, l'hypertension, les cardiopathies, l'insuffisance cardiaque congestive, les accidents vasculaires cérébraux, le diabète et l'exposition à des médicaments cardiovasculaires. Les sujets et et les témoins ont été appariés à l'aide du score de propension calculé.

Résultats Le taux de mortalité global à 30 jours était de 3,5\% (31/883 patients). Le taux brut de mortalité chez les patients ayant pris un inhibiteur du SRA était de 5,8\% (21/359) contre 1,9\% (10/524) chez les patients n'y ayant pas été exposés (rapport des cotes de 3,2, avec intervalles de confiance de $95 \%$ [IC 95$]$ 1,5-6,7; P<0,001). L'analyse de 261 paires de patients appariés par scores de propension a permis de démontrer un taux de mortalité à 30 jours de 6,1\% (16/261) pour les patients ayant pris un inhibiteur du SRA contre 1,5\% (4/261) pour les patients non exposés $(P=0,008)$. Le rapport de cotes estimé pour le taux de mortalité à 30 jours associé à l'inhibition du SRA était de 5,0 (IC 95 1,4-27).

Conclusions L'examen de 883 cas de chirurgie en cas d'AAA a révélé une augmentation du taux de mortalité associé à l'inhibition préopératoire du SRA. Une meilleure connaissance de la pharmacologie peropératoire et de la physiologie de l'inhibition du SRA et d'autres études sont nécessaires pour identifier la causalité.

Angiotensin converting enzyme (ACE) inhibitors and angiotensin receptor antagonists (ARAs) are used to treat hypertension, congestive heart failure (CHF) and myocardial infarction (MI), reducing mortality and improving quality of life. ${ }^{1}$ Inhibitors of ACE and ARAs are popular and effective with over 130,000 patients studied in randomized controlled trials (RCTs). ${ }^{2}$ However, the conclusions of these RCTs might not be applicable to the situation of surgical patients, because none of the RCTs examined the effects of anesthesia and perioperative care.

Perioperative blockade of the renin-angiotensin system (RAS), defined as preoperative exposure to ACE inhibitors and ARAs, remains controversial because the area has been poorly studied. The 2007 American College of Cardiology American Heart Association guidelines ${ }^{3}$ advise caution using ACE inhibitors perioperatively in renally impaired patients citing increased risk of renal failure. ${ }^{4}$ Some physicians recommend holding ACE inhibitors or ARAs prior to surgery to prevent intraoperative refractory hypotension. ${ }^{5,6}$

Anesthetized patients depend heavily on the RAS to maintain blood pressure. ${ }^{7}$ Hypovolemia, hyponatremia, and anemia activate the RAS to maintain blood pressure. ${ }^{8}$ Intraoperative hypotension induced by ACE inhibitors has been reported in one large study ${ }^{9}$ and in a meta-analysis. ${ }^{10}$
The ACE inhibitors have been studied in patients with CHF undergoing vascular surgery. ${ }^{11}$ Correction for thirteen medical factors showed that ACE inhibitor exposure was protective in patients with left ventricular dysfunction (odds ratio $0.33 ; 95 \%$ confidence intervals $\left[\mathrm{CI}_{95}\right]$ 0.12$0.91 ; P=0.03) .{ }^{11}$ However, Miceli et al. have shown that perioperative ACE inhibitor therapy is associated with a doubling of the mortality rate in patients undergoing coronary artery bypass grafting surgery (CABG). ${ }^{12}$ The purpose of this study was to test the hypothesis that preoperative RAS blockade is safe in vascular surgery patients, using 30-day postoperative mortality as the primary end point.

\section{Methods}

Following Research Ethics Board approval, consent was obtained from the attending surgeons to review the medical charts of patients undergoing abdominal aortic aneurysm (AAA) repair at two teaching hospitals from January 1, 1998 to December 31, 2005. Patients were identified for possible inclusion into the cohort based on operative bookings and the following inclusion criteria: age $>50 \mathrm{yr}$, elective AAA repair, or urgent surgery with adequate medical workup. Patients were excluded for the following reasons: trauma, emergency surgery, sepsis, combined AAA and non-vascular surgery, and surgery on bypass.

One physician reviewed all charts and abstracted information onto data sheets. Data were entered into Microsoft Excel 2003 (Microsoft Corp., Redmond, OR, USA) using Filemaker Pro 5.0 (Filemaker Inc., Santa Clara, CA, USA) computer software for conversion to a data file for statistical analysis.

The information collected included age, sex, medical history (cardiac, respiratory, renal, neurological, and endocrine), preoperative consultation and testing, vital signs, weight, renal function, preoperative medications, surgeon, and anesthetic techniques. Postoperative complications were also entered: death, arrest, arrhythmia, $\mathrm{CHF}$, increased troponin, renal failure, stroke, and other complications.

Medications were grouped using the following classes: ACE inhibitors, ARAs, beta-blockers, calcium channel blockers $(\mathrm{CaCB})$, diuretics, nitrates, non-steroidal antiinflammatory drugs (NSAIDs), cyclooxygenase II inhibitors (COX-2 s), and HMG-CoA inhibitors (statins). An assumption was made that the patients were taking the medications as directed by the preoperative assessment clinic staff. The normal recommendation was to take all cardiac medications with the exception of diuretics, which were held on the day of surgery; NSAIDs and COX-2 inhibitors were held for five days prior to surgery. 
A patient was considered to have a given medical condition under any of the following circumstances: self report, positive diagnostic testing, diagnosis in old charts, and report of the condition in preoperative consultations or in the attending anesthesiologist's note. Creatinine clearance $(\mathrm{Cr} \mathrm{Cl})$ was calculated using the Cockcroft-Gault formula. ${ }^{13}$

Postoperative complications were recorded based on physician diagnosis recorded in the medical chart. Infections were diagnosed based on positive laboratory culture results, even if not recorded in the medical notes. A postoperative MI - increased troponin was recorded as the result of a physician diagnosis of MI or a laboratory troponin I concentration $>0.3 \mathrm{ng} . \mathrm{L}^{-1}$ and either patient symptoms or ECG changes.

\section{Study end point and sample size}

Thirty-day mortality was the primary end point used to assess the safety of RAS blockade. A pilot study of the first 122 charts was undertaken. Seventy-one patients met the inclusion criteria with an observed death rate of 9.8\% (7/71 patients), $29 \%$ in ACE/ARA exposed patients (5/17) vs $3.7 \%$ in unexposed patients $(2 / 54)(P=0.002)$. However, the subjects were not well matched. The observed death rate was greater than the expected rate of $4 \%$. There was considerable uncertainty in the estimated mortality rate, especially in RAS blocked patients.

Modelling a range of death rates using PASS 2002 (NCSS LLC, Kaysville, UT, USA) showed that 780 pairs would be needed to detect a difference of $4 \%$ in death rate associated with RAS blockade (power 0.8; alpha $=0.05$ ), assuming $15 \%$ of pairs were discordant. This number would decrease to 350 pairs if the difference in death rate was increased to $6 \%$. It was decided to review eight years of consecutive cases (approximately 1,300 charts) expecting to find approximately 900 to 1,000 patients comprising cohort for analysis.

\section{Statistical analysis}

Data was analyzed using NCSS 2007 (NCSS LLC, Kaysville, UT, USA) and SAS 9.1 (SAS Inc, Cary, NC, USA). Continuous data variable differences were tested by Student's $t$ test. Dichotomous data differences were tested by Chi square test or Fisher's modification. SAS 9.1 was used to perform the propensity score match and subsequent statistics on the matched data set, and the McNemar score was used to assess differences between exposed and unexposed subjects. Odds ratios and confidence intervals for matched pairs were estimated using a standard method. ${ }^{14}$ Comparisons of 30-day mortality (primary end point) and major postoperative complications were planned at the start of the study. Data are reported as mean \pm standard deviation unless otherwise indicated.

To avoid selection bias and confounding factors, RAS blocked subjects and unblocked patients were matched using a propensity score system. ${ }^{15}$ A logistic regression analysis of the data set (883 patients and 49 possible factors) using SAS 9.1 (SAS Inc., Cary, NC, USA) identified predictors (all $P<0.05$ ) of RAS blockade: hypertension, stroke, CHF, diabetes, and heart disease (a combined term comprised of any history of previous MI, previous CABG, arrhythmias, and/or angina). A second logistic regression analysis of the data set identified predictors (all $P<0.05$ ) of mortality: age, creatinine, diabetes, ACE/ARA, and diuretic exposure. Factors affecting perioperative mortality were considered for inclusion in the model, especially those differing between the RAS blocked and unblocked groups. The model developed predicting preoperative RAS blockade included the following terms: age, sex, creatinine, $\mathrm{CHF}$, heart disease, hypertension, stroke, and preoperative cardiovascular medication exposures (beta-blockers, $\mathrm{CaCB}$, diuretics, and $\mathrm{HMG}-\mathrm{CoA}$ reductase inhibitors [statins]). A propensity score (from 0 to 1 ) representing the likelihood of RAS blockade was calculated for each subject. An unexposed subject was matched to an RAS blocked subject using the MEANS procedure of the SAS 9.1 program (propensity score within 0.1 ). In 19 patients, the preoperative serum creatinine was estimated as $103.15 \mu \mathrm{mol} \cdot \mathrm{L}^{-1}$.

\section{Results}

Subjects

According to operating room bookings, 1,320 patients underwent AAA repair from January 1, 1998 to December 31, 2005. Manual review of charts identified 883 subjects meeting inclusion criteria. There were 437 exclusions for the following reasons: other vascular procedure performed (259), emergency surgery (157), age $<50 \mathrm{yr}$ (8), missing charts (4), cancelled surgery (2), and other (7). Subject characteristics, medical history, and the results of the propensity matching process are summarized in Table 1 .

Preoperative medication exposures

Examination of preoperative medication exposures revealed that 306 of 883 subjects (34\%) were exposed to ACE inhibitors, and 60 of 883 subjects (7\%) were exposed to ARA agents. Eight subjects were exposed to both ACE inhibitors and ARAs. The exposures of subjects to different classes of medications are reported in Table 2, including 
Table 1 Patient characteristics - unmatched data and propensity score matched subjects

\begin{tabular}{|c|c|c|c|c|c|}
\hline \multirow[t]{2}{*}{ Patient data } & \multicolumn{3}{|c|}{ Unmatched data } & \multicolumn{2}{|c|}{ Propensity score matched subjects } \\
\hline & $\begin{array}{l}\text { Whole group } \\
(883)\end{array}$ & $\begin{array}{l}\text { RAS blockade } \\
\text { (359) }\end{array}$ & $\begin{array}{l}\text { No RAS blockade } \\
\text { (524) }\end{array}$ & $\begin{array}{l}\text { RAS blockade } \\
(261)\end{array}$ & $\begin{array}{l}\text { No RAS blockade } \\
\text { (261) }\end{array}$ \\
\hline Male & $726(82 \%)$ & $298(83 \%)$ & $428(82 \%)$ & $210(81 \%)$ & $212(81 \%)$ \\
\hline Age $(y r)$ & $72(7)$ & $72(7)$ & $72(7)$ & $72(7)$ & $72(7)$ \\
\hline Weight (kg) & $80(16)$ & $81(16)$ & $79(15)$ & $81(17)$ & $80(15)$ \\
\hline Heart rate $\left(\min ^{-1}\right)$ & $70(13)$ & $69(13)$ & $70(12)$ & $70(13)$ & $70(12)$ \\
\hline Systolic blood pressure (mmHg) & $138(20)$ & $139(21)$ & $137(19)$ & $139(21)$ & $141(19)$ \\
\hline Diastolic blood pressure $(\mathrm{mmHg})$ & $80(21)$ & $79(11)$ & $80(25)$ & $79(11)$ & $80(12)$ \\
\hline Mean preoperative $\mathrm{Hgb}\left(\mathrm{g} \cdot \mathrm{L}^{-1}\right)$ & $138(16)$ & $136(16)$ & $139(15)$ & $136(16)$ & $139(15)$ \\
\hline $\mathrm{CrCl}\left(\mathrm{mL} \cdot \mathrm{min}^{-1}\right)$ & $73(30)$ & $71(31)$ & $74(28)$ & $71(30)$ & $70(28)$ \\
\hline Creatinine $(\mu \mathrm{moL})$ & $103(56)$ & $109(60)$ & $99(52)$ & $107(63)$ & $107(68)$ \\
\hline \multicolumn{6}{|l|}{ Medical conditions } \\
\hline Hypertension & $590(67 \%)$ & $319(89 \%)$ & $271(52 \%)$ & $224(86 \%)$ & $235(90 \%)$ \\
\hline Heart disease & $428(49 \%)$ & $204(57 \%)$ & $224(43 \%)$ & $140(54 \%)$ & $140(54 \%)$ \\
\hline Previous MI & $269(30 \%)$ & $134(37 \%)$ & $135(26 \%)$ & $93(36 \%)$ & $83(32 \%)$ \\
\hline Angina & $176(20 \%)$ & $79(22 \%)$ & $97(19 \%)$ & $46(18 \%)$ & $61(23 \%)$ \\
\hline Arrhythmia & $117(13 \%)$ & $69(19 \%)$ & $48(9 \%)$ & $47(18 \%)$ & $29(11 \%)$ \\
\hline Afib & $79(9 \%)$ & $45(13 \%)$ & $34(7 \%)$ & $30(12 \%)$ & $19(7 \%)$ \\
\hline $\mathrm{CHF}$ & $34(4 \%)$ & $25(7 \%)$ & $9(2 \%)$ & $14(5.4 \%)$ & $8(3.1 \%)$ \\
\hline Valvular heart disease & $31(4 \%)$ & $18(5 \%)$ & $14(3 \%)$ & $9(3.4 \%)$ & $9(3.4 \%)$ \\
\hline Previous CABG & $120(13 \%)$ & $66(18 \%)$ & $54(10 \%)$ & $48(18 \%)$ & $41(16 \%)$ \\
\hline Renal impairment & $154(19 \%)$ & $82(21 \%)$ & $77(15 \%)$ & $53(20 \%)$ & $51(20 \%)$ \\
\hline Renal failure on HD & $5(1 \%)$ & $5(1 \%)$ & $0(0 \%)$ & $3(1.2 \%)$ & $0(0 \%)$ \\
\hline Stroke & $57(7 \%)$ & $38(11 \%)$ & $19(4 \%)$ & $15(5.7 \%)$ & $13(5.0 \%)$ \\
\hline TIA & $51(6 \%)$ & $19(5 \%)$ & $32(6 \%)$ & $16(6.1 \%)$ & $21(8.0 \%)$ \\
\hline Seizures & $11(1 \%)$ & $2(1 \%)$ & $9(2 \%)$ & $1(0.4 \%)$ & $6(2.3 \%)$ \\
\hline Any smoking history & $756(86 \%)$ & $308(86 \%)$ & $448(85 \%)$ & $220(84 \%)$ & $214(82 \%)$ \\
\hline Active smokers & $301(21 \%)$ & $115(32 \%)$ & $186(36 \%)$ & $82(32 \%)$ & $84(31 \%)$ \\
\hline Pack years & $48(21)$ & $47(21)$ & $48(21)$ & $48(21)$ & $50(21)$ \\
\hline COPD & $184(21 \%)$ & $78(22 \%)$ & $105(20 \%)$ & $56(22 \%)$ & $48(18 \%)$ \\
\hline Diabetes & $119(13 \%)$ & $71(20 \%)$ & $48(9 \%)$ & $37(14 \%)$ & $30(12 \%)$ \\
\hline Thyroid disease & $80(9 \%)$ & $32(9 \%)$ & $48(9 \%)$ & $25(9.6 \%)$ & $24(9.2 \%)$ \\
\hline Propensity score & & & & $0.49(0.16)$ & $0.48(0.16)$ \\
\hline
\end{tabular}

Data are reported as mean (standard deviation) or number (\%). RAS = renin-angiotensin system; RAS blockade = exposure to angiotensin converting enzyme (ACE) inhibitors or angiotensin receptor antagonists (ARA); No RAS blockade = no exposure to ACE inhibitors or ARA; $\mathrm{CaCB}=$ calcium channel blocker, $\mathrm{Cr} \mathrm{Cl}=$ creatinine clearance; heart disease (composed of previous MI, previous CABG, angina, and arrhythmias); $\mathrm{MI}=$ myocardial infarction; Afib = atrial fibrillation; $\mathrm{CHF}=$ congestive heart failure; CABG = coronary artery bypass grafting, $\mathrm{HD}=$ hemodialysis; Statin $=$ HMG Co-A reductase inhibitor; TIA $=$ transient ischemic attack COPD $=$ chronic obstructive pulmonary disease

propensity score matched subjects. The details of the propensity matching process are presented in Table 3 .

Surgeons and anesthetic techniques

Prior to considering further analysis, we searched for differences in mortality related to surgeon or choice of anesthetic techniques employed. None were found. All 883 patients received a general anesthetic with inhaled agents being used in 882 (99.9\%); one patient had malignant hyperthermia. Thoracic epidurals were placed in $715(81 \%)$ patients and used during the anesthetic in $243(28 \%)$ cases. Mean estimated blood loss was $1,267 \pm 1,083 \mathrm{~mL}$. Volume of fluid administered was $5,583 \pm 3,282 \mathrm{~mL}$, and fluid balance was positive by $3,918 \pm 2,303 \mathrm{~mL}$. Blood products were received and/or a cell saver was used in 521 patients $(59 \%)$. 
Table 2 Preoperative medications

\begin{tabular}{|c|c|c|c|c|c|c|}
\hline \multirow[t]{2}{*}{ Drug class } & \multicolumn{4}{|l|}{ Unmatched data } & \multicolumn{2}{|c|}{ Propensity score matched subjects } \\
\hline & Whole group (883) & RAS blockade (359) & No RAS blockade (524) & $P$ value & RAS blockade (261) & No RAS blockade (261) \\
\hline $\mathrm{ACE}^{*}$ & $306(35 \%)$ & $306(85 \%)$ & 0 & & 225 & 0 \\
\hline $\mathrm{ARA}^{*}$ & $60(7 \%)$ & $60(18 \%)$ & 0 & & 40 & 0 \\
\hline Beta-blocker & $376(43 \%)$ & $174(49 \%)$ & $202(39 \%)$ & 0.006 & $126(48 \%)$ & $129(49 \%)$ \\
\hline $\mathrm{CaCB}$ & $268(30 \%)$ & $117(33 \%)$ & $151(29 \%)$ & 0.227 & $88(34 \%)$ & $102(39 \%)$ \\
\hline Diuretics & $179(20 \%)$ & $103(29 \%)$ & $76(15 \%)$ & $<0.001$ & $71(27 \%)$ & $62(24 \%)$ \\
\hline Statin & $365(41 \%)$ & $175(49 \%)$ & $190(36 \%)$ & $<0.001$ & $116(44 \%)$ & $117(45 \%)$ \\
\hline NSAIDs & $389(44 \%)$ & $170(47 \%)$ & $219(42 \%)$ & 0.135 & $118(45 \%)$ & $117(45 \%)$ \\
\hline Nitrates & $106(12 \%)$ & $50(14 \%)$ & $56(11 \%)$ & 0.150 & $32(12 \%)$ & $32(12 \%)$ \\
\hline $\mathrm{COX} 2$ & $43(4 \%)$ & $14(4 \%)$ & $19(4 \%)$ & 0.873 & $12(4.2 \%)$ & $10(4.2 \%)$ \\
\hline
\end{tabular}

Data are reported as number $(\%) .{ }^{*}$ Eight patients were taking both an ACE inhibitor and an ARA. Four patients were taking ACE inhibitors and ARAs in the propensity score matched data set. RAS = renin-angiotensin system; RAS Blockade = exposure to angiotensin converting enzyme $(\mathrm{ACE})$ inhibitors or angiotensin receptor antagonists (ARA); No RAS blockade $=$ no exposure to ACE inhibitors or $\mathrm{ARA}$; CaCB = calcium channel blocker; Statin $=$ HMG CoA reductase inhibitor; NSAIDs = non-steroidal anti-inflammatory drug; COX2 = cyclo-oxygenase 2 inhibitor

\section{Postoperative outcomes}

Postoperative outcomes for unmatched and propensity matched pairs are summarized in Table 4. Twenty-one of 359 patients with RAS blockade (5.8\%) died within 30 days of surgery vs 10/524 (1.9\%) of unblocked subjects $(P<0.002)$. Data for secondary outcomes and common postoperative complications for ACE/ARA exposed subjects and unexposed subjects are reported in Table 4.

Propensity matched pairs outcomes are also reported in Table 4 and distribution of pairs in Table 3. The matching process afforded 261 pairs of subjects, and analysis revealed 16 deaths $(6.1 \%)$ in RAS blocked patients and four deaths $(1.5 \%)$ in unblocked patients. One pair was concordant for death. The McNemar Score was calculated as $8.0(P=0.008)$. The estimated odds ratio for increased mortality in the matched sample was 5; $\mathrm{CI}_{95}$ 1.4-27. However, the matching did not control for hypertension; $94 \%$ of pairs were concordant (222 hypertensive and 24 not hypertensive) and 15 pairs discordant (two RAS blocked and 13 unexposed) $(P=0.005)$. Causes of death and associated conditions are reported in Table 5 .

Mortality associated with medical conditions and medication exposures

Unadjusted odds ratios for 30-day mortality were calculated for medical conditions and medication exposures using the entire data set of 883 patients. Only two medical conditions were associated with 30-day mortality: diabetes (odds ratio 2.8; $\mathrm{CI}_{95}$ 1.2-6.1) and $\mathrm{CHF}$ (odds ratio 4.1; $\mathrm{CI}_{95}$ 1.3-12.3). Only two medication exposures were associated with increased mortality: ACE inhibitor/ARA exposure
21/359 (5.8\%) vs 10/524 (1.9\%) (odds ratio 3.2; $\mathrm{CI}_{95} 1.5$ $6.9)$, and diuretic exposure $15 / 164(9.1 \%)$ exposed vs $16 /$ $688(2.3 \%)$ unexposed (odds ratio 3.9; $\mathrm{CI}_{95}$ 1.90-8.11).

\section{Discussion}

Perioperative use of ACE inhibitors or ARAs remains controversial. Randomized controlled trials demonstrating the clinical effectiveness of ACE inhibitors and ARAs in the medical setting may not be applicable perioperatively, because none of the RCTs examined the effects of anesthesia and perioperative care on RAS blockade. It is not known if a drug interaction exists between RAS blocking medications and inhaled anesthetic agents. A possible explanation for intraoperative hypotension in RAS blocked patients is impaired $\mathrm{Ca}^{2+}$ binding in vascular smooth muscle cells. Vascular myocyte contraction can be initiated by angiotensin 2 binding to the angiotensin 1 (AT1) receptor. ${ }^{16}$ Protein kinase $\mathrm{C}$ (PKC) is involved in multiple intracellular pathways, including sensitizing the AT1 and angiotensin 2 (AT2) receptors. ${ }^{17}$ Inhaled anesthetics inhibit PKC causing decreased activity of the AT1 receptor and increased activity of the AT2 receptor causing decreased vascular tone. ${ }^{16-19}$ Bradykinin has also been implicated as a possible intermediary. ${ }^{20}$

In the present study, RAS blockade was associated with an increased mortality within 30 days of surgery in vascular surgery patients (uncorrected odds ratio 3.2; $\mathrm{CI}_{95}$ 1.56.9). Differences in underlying medical conditions and medication exposures between RAS blocked patients and unexposed patients were identified. Separation of the effects of a medication from the medical condition for 
Table 3 Matched pairs analysis - distribution of concordant and discordant matched pairs for preoperative factors in propensity score matching and postoperative outcomes. The number of pairs was 261

\begin{tabular}{|c|c|c|c|c|}
\hline \multicolumn{2}{|c|}{ Concordant pairs } & \multicolumn{2}{|l|}{ Discordant pairs } & \multirow{2}{*}{$\begin{array}{l}\text { McNemar } \\
P \text { value }\end{array}$} \\
\hline $\begin{array}{l}\text { Factor present } \\
\text { both subjects }\end{array}$ & $\begin{array}{l}\text { Factor absent } \\
\text { both subjects }\end{array}$ & $\begin{array}{l}\text { Factor present } \\
\text { in RAS blocked blockade } \\
\text { but absent in no RAS } \\
\text { unblocked blockade }\end{array}$ & $\begin{array}{l}\text { Factor absent } \\
\text { in RAS blocked } \\
\text { blockade but } \\
\text { present in no RAS } \\
\text { unblocked blockade }\end{array}$ & \\
\hline
\end{tabular}

\begin{tabular}{|c|c|c|c|c|c|}
\hline \multicolumn{6}{|c|}{ Preoperative medical conditions } \\
\hline Sex (Male) & 182 & 21 & 30 & 28 & 0.90 \\
\hline Hypertension & 222 & 24 & 2 & 13 & 0.007 \\
\hline Heart disease & 96 & 77 & 44 & 44 & 1.0 \\
\hline $\mathrm{CHF}$ & 3 & 242 & 11 & 5 & 0.21 \\
\hline Stroke & 3 & 236 & 12 & 10 & 0.83 \\
\hline Diabetes & 12 & 206 & 25 & 18 & 0.36 \\
\hline \multicolumn{6}{|c|}{ Preoperative medication exposures } \\
\hline Beta-blockers & 85 & 91 & 41 & 44 & 0.83 \\
\hline $\mathrm{CaCB}$ & 40 & 111 & 48 & 62 & 0.21 \\
\hline Diuretics & 70 & 98 & 46 & 47 & 1.0 \\
\hline Statins & 24 & 152 & 47 & 38 & 0.38 \\
\hline \multicolumn{6}{|l|}{ Post operative outcomes } \\
\hline Death $<30$ days & 1 & 242 & 15 & 3 & 0.008 \\
\hline MI/increased troponin & 6 & 180 & 40 & 35 & 0.645 \\
\hline Postoperative heart failure & 5 & 220 & 20 & 16 & 0.618 \\
\hline Postoperative stroke & 0 & 255 & 5 & 1 & 0.219 \\
\hline Postoperative renal failure & 1 & 202 & 30 & 28 & 0.896 \\
\hline Postoperative hemodialysis & 0 & 247 & 12 & 2 & 0.013 \\
\hline
\end{tabular}

Data are reported as numbers. RAS = renin-angiotensin system; RAS blockade $=$ exposure to angiotensin converting enzyme (ACE) inhibitors or angiotensin receptor antagonists (ARA); No RAS blockade = no exposure to ACE inhibitors or ARA; CaCB = calcium channel blocker; $\mathrm{CHF}=$ congestive heart failure; Heart disease (composed of previous myocardial infarction, previous coronary artery bypass grafting, angina, and arrhythmias); MI/increased troponin = postoperative myocardial infarction (troponin I $>0.3 \mathrm{ng} \cdot \mathrm{L}^{-1}$ ); Statins = HMG Co-A reductase inhibitors

which it is prescribed is problematic. The possibility exists that ACE/ARAs are prescribed to patients who are medically less fit, which would account for the observed differences. Differences in underlying medical conditions were addressed by propensity score matching predicting the preoperative likelihood that a patient would be exposed to an ACE inhibitor or ARA prior to surgery.

Matching based only on age and sex, as was done in other studies, ${ }^{21}$ predisposes towards poor matching of subjects. To reduce selection bias and confounding, a propensity matching system was developed to match exposed and unexposed subjects. Logistic regression analysis of the 883 cases identified five predictors of ACE inhibitor/ARA exposure: hypertension, stroke, CHF, diabetes, and heart disease. Hypertension was the strongest predictor of preoperative ACE/ARA exposure. Additional analysis of the data set identified preoperative diuretic exposure as a factor associated with mortality. Cardiovascular medication exposures were different between RAS blocked and unblocked patient populations. A propensity score model was developed that incorporated the above information and known preoperative predictors thought to be associated with mortality in this patient population. ${ }^{22-30}$ The model incorporated the following terms: age, sex, creatinine, hypertension, heart disease, CHF, diabetes, stroke, and cardiovascular medication exposures (betablocker, $\mathrm{CaCB}$, diuretic, and statins). The patients were then matched on the calculated propensity score predicting the likelihood that patients would be preoperatively prescribed an ACE inhibitor or ARA to block the RAS.

This matching method afforded 261 pairs of subjects. The 30-day mortality of the RAS blocked patients was $16 / 261$ deaths $(6.1 \%)$ compared with $4 / 261(1.5 \%)$ for the unblocked patients (odds ratio 5.0; $\mathrm{CI}_{95} 1.4-27 ; P=0.008$ ). The patients were well matched for all medical conditions except hypertension, despite having 94\% of the pairs matched concordantly. There were 15 discordant pairs for a preoperative diagnosis of hypertension, two pairs RAS blocked vs 13 pairs unblocked (McNemar score 8; $P=$ 0.008). 
Table 4 Postoperative outcomes and RAS blockade

\begin{tabular}{|c|c|c|c|c|c|c|}
\hline \multirow[t]{2}{*}{ Outcome } & \multicolumn{3}{|c|}{ Unmatched Data } & \multicolumn{3}{|c|}{ Propensity Score Matched Subjects } \\
\hline & $\begin{array}{l}\text { Whole Group } \\
\text { (883) }\end{array}$ & $\begin{array}{l}\text { RAS Blockade } \\
\text { (358) }\end{array}$ & $\begin{array}{l}\text { No RAS Blockade } \\
(525)\end{array}$ & $\begin{array}{l}\text { RAS Blockade } \\
\text { (261) }\end{array}$ & $\begin{array}{l}\text { No RAS Blockade } \\
\text { (261) }\end{array}$ & $\begin{array}{l}\text { McNemar } \\
P \text { Value }\end{array}$ \\
\hline Death $<30$ days & $31(4 \%)$ & $21(6 \%)$ & $10(2 \%)$ & $16^{*}(6.3 \%)$ & $4^{*}(1.8 \%)$ & 0.008 \\
\hline $\begin{array}{l}\text { All in hospital } \\
\text { deaths }\end{array}$ & $38(4 \%)$ & $25(7 \%)$ & $13(3 \%)$ & & & \\
\hline Cardiac arrest & $23(3 \%)$ & $14(4 \%)$ & $9(2 \%)$ & & & \\
\hline Arrhythmia & $118(13 \%)$ & $45(13 \%)$ & $73(14 \%)$ & & & \\
\hline $\begin{array}{l}\text { MI/increased } \\
\text { troponin }\end{array}$ & $149(17 \%)$ & $74(21 \%)$ & $75(14 \%)$ & $46(18 \%)$ & $41(16 \%)$ & 0.645 \\
\hline $\mathrm{CHF}$ & $87(10 \%)$ & $47(13 \%)$ & $40(8 \%)$ & $25(9.6 \%)$ & $21(8.0 \%)$ & 0.618 \\
\hline Stroke & $10(1 \%)$ & $5(1 \%)$ & $5(1 \%)$ & $5(1.9 \%)$ & $1(0.4 \%)$ & 0.219 \\
\hline Renal failure & $96(10 \%)$ & $49(14 \%)$ & $47(9 \%)$ & $31(12 \%)$ & $29(11 \%)$ & 0.896 \\
\hline New dialysis & $24(3 \%)$ & $17(5 \%)$ & $7(1 \%)$ & $12(4.6 \%)$ & $2(0.8 \%)$ & 0.013 \\
\hline Any infection & $144(16 \%)$ & $58(16 \%)$ & $86(16 \%)$ & & & \\
\hline Pneumonia & $82(9 \%)$ & $32(9 \%)$ & $50(10 \%)$ & & & \\
\hline UTI & $12(1 \%)$ & $6(2 \%)$ & $6(1 \%)$ & & & \\
\hline Re-operation & $57(6 \%)$ & $25(7 \%)$ & $32(6 \%)$ & & & \\
\hline Delirium & $115(13 \%)$ & $46(13 \%)$ & $69(13 \%)$ & & & \\
\hline Prolonged ileus & $64(7 \%)$ & $21(6 \%)$ & $43(8 \%)$ & & & \\
\hline DVT & $8(2 \%)$ & $2(1 \%)$ & $6(1 \%)$ & & & \\
\hline PE & $4(1 \%)$ & $0(0 \%)$ & $4(1 \%)$ & & & \\
\hline Any complication & $714(81 \%)$ & $299(83 \%)$ & $415(80 \%)$ & & & \\
\hline
\end{tabular}

Data are reported as number $(\%)$; Both patients died in one pair of the matched data

RAS = renin-angiotensin system; RAS blockade = exposure to angiotensin converting enzyme (ACE) inhibitors or angiotensin receptor antagonists (ARA); No RAS blockade = no exposure to ACE inhibitors or ARA; Death $<30$ days = death within 30 days of surgery; $\mathrm{MI} /$ increased troponin $=$ diagnosed MI or troponin I over $0.3 \mathrm{ng} \cdot \mathrm{L}^{-1 \dagger}$, and either patient symptoms or electrocardiogram (ECG) confirmed changes in ECG trace; $\mathrm{CHF}=$ congestive heart failure; DVT = deep vein thrombosis; PE = pulmonary embolus; ICU = intensive care unit (same as critical care unit); UTI = urinary tract infection. All in hospital deaths represents all patients that died without discharge from hospital from the day admitted for AAA surgery: data range 1 to 148 days

$\dagger$ In the majority of cases, the increase in troponin I was small $\left(<3 \mathrm{ng} \cdot \mathrm{L}^{-1}\right)$

Analysis of known medical risk factors ${ }^{22-30}$ was performed on the entire cohort to assess perioperative mortality. In this data set only, CHF, diabetes, and poor renal function $\left(\mathrm{Cr} \mathrm{Cl}<45 \mathrm{~mL} \cdot \mathrm{min}^{-1}\right.$ ) were predictors of 30-day mortality. Hypertension was not a predictor of mortality in this data set nor is hypertension a known predictor of mortality in this patient population. Given the background information from the medical literature and the high percentage of concordant pairs matched with hypertension, it seems unlikely that hypertension played a major role in the observed increased mortality, but nonetheless, hypertension remains a possible confounding variable.

Nine diabetics died in this cohort of patients. Preoperative diagnosis of diabetes was used as a matching variable, and the matching methodology appears to have controlled for diabetes. However, none of the RAS unblocked diabetics in the data set died. The possibility exists that diabetes may be playing some role in the observed increased rate of death due to RAS blockade despite good matching for diabetes.
Patients exposed to ACE inhibitors/ARA agents are likely to be exposed to other cardiovascular medications: beta-blockers, diuretics, and statins (all $P<0.01$ ). Although controversial, possible protective effects of some cardiovascular medications were considered. In the present study, exposure to beta-blockers, ${ }^{31-34}$ statins, ${ }^{35}$ or $\mathrm{CaCB}^{36}$ showed no effect on mortality. Only ACE inhibitors/ARA exposure and diuretic exposure were predictive of increased 30-day mortality.

Keterpal et al. ${ }^{9}$ showed that exposure to ACE inhibitors and diuretics increased intraoperative hypotension but did not increase the rate of postoperative complications. In the present study, patients exposed to ACE/ARA agents were more likely to be exposed to diuretics: $103 / 359$ (29\%) in the ACE/ARA exposed patients vs 76/524 (15\%) in the non ACE/ARA exposed $(P<0.001)$. Perioperative hypotension may be a possible contributor to increased mortality, but it was not tracked well in our data set.

In this study, preoperative diuretic exposure (all types grouped together) was a significant predictor of death 
Table 5 Causes of death and associated factors

\begin{tabular}{|c|c|c|c|c|c|}
\hline \multirow[t]{2}{*}{ Cause of death } & \multicolumn{3}{|c|}{ Unmatched data } & \multicolumn{2}{|c|}{ Propensity score matched subjects } \\
\hline & $\begin{array}{l}\text { Whole Group } \\
(31)\end{array}$ & $\begin{array}{l}\text { RAS blockade } \\
(21)\end{array}$ & $\begin{array}{l}\text { No RAS blockade } \\
\text { (10) }\end{array}$ & $\begin{array}{l}\text { RAS blockade } \\
\text { (16) }\end{array}$ & $\begin{array}{l}\text { No RAS blockade } \\
\text { (4) }\end{array}$ \\
\hline Cardiac cause & $17(55 \%)$ & $9(42 \%)$ & $8(80 \%)$ & $11(53 \%)$ & $4(100 \%)$ \\
\hline - MI & $9(29 \%)$ & $10(47 \%)$ & $7(70 \%)$ & $7(44 \%)$ & $3(75 \%)$ \\
\hline - Cardiac arrest & $8(26 \%)$ & $7(33 \%)$ & $4(40 \%)$ & $4(25 \%)$ & $1(25 \%)$ \\
\hline Respiratory cause & $2(6 \%)$ & $1(13 \%)$ & $1(10 \%)$ & $0(0 \%)$ & $0(0 \%)$ \\
\hline - Pulmonary embolus & $1(3 \%)$ & $0(0 \%)$ & $1(10 \%)$ & $0(0 \%)$ & $0(0 \%)$ \\
\hline MSOF Present & $12(38 \%)$ & $10(48 \%)$ & $2(20 \%)$ & $8(50 \%)$ & $0(0 \%)$ \\
\hline Renal failure present & $16(52 \%)$ & $12(62 \%)$ & $4(40 \%)$ & $9(56 \%)$ & $0(0 \%)$ \\
\hline New dialysis present & $8(26 \%)$ & $7(33 \%)$ & $1(10 \%)$ & $5(31 \%)$ & $0(0 \%)$ \\
\hline Sepsis present & $6(16 \%)$ & $5(24 \%)$ & $1(10 \%)$ & $4(25 \%)$ & $1(25 \%)$ \\
\hline $\begin{array}{l}\text { Well enough for transfer to floor } \\
\text { bed prior to death }\end{array}$ & $11(35 \%)$ & $5(24 \%)$ & $6(60 \%)$ & $1(6.3 \%)$ & $3(75 \%)$ \\
\hline
\end{tabular}

Data will not sum to $100 \%$, percentages are calculated within columns with denominator determined by number of patients within column. Some patients had multiple counts

RAS = renin-angiotensin system; RAS blockade = exposure to angiotensin converting enzyme (ACE) inhibitors or angiotensin receptor antagonists (ARA); No RAS blockade $=$ no exposure to ACE Inhibitors or ARA; MI/cardiogenic shock = cause of death directly related to myocardial infarction and including cardiogenic shock; MSOF = multi-system organ failure

within 30 days of surgery (odds ratio $3.9 ; \mathrm{CI}_{95}$ 1.9-8.1). The propensity matching system achieved good matching for all preoperative cardiovascular medication exposures, including diuretics. Based on this data set, it appears that diuretics are not playing a role in perioperative RAS blockade associated mortality. However, the data set may not be large enough to rule out an interaction with diuretics and medications that block the RAS.

In regards to postoperative outcomes, approximately $80 \%$ of patients suffered a postoperative complication, albeit the majority of complications were minor. In addition to increased mortality, RAS blocked patients were more likely to need postoperative hemodialysis (McNemar score 7.14; $P<0.013$ ) despite not having a higher rate of postoperative renal failure. The matched group of patients did not have increased rates of other common major postoperative complications: MI, CHF, renal failure, and stroke. A higher percentage of RAS blocked patients died with multi-system organ failure (Table 5).

There are several limitations related to this study. The use of retrospective data from chart review to study clinical questions has marked limitations, for example, only association but not causality can be demonstrated. Another weakness of chart review studies is the inability to adequately control for exposures other than the exposure of interest. The best way to test the perioperative safety of RAS blockade would be to conduct a prospective randomized trial in patients undergoing major surgeries with sufficient washout of active metabolites (circa ten days).
In conclusion, we assessed patients with preoperative exposure to ACE inhibitors and ARA agents in terms of their outcomes with perioperative blockade of the RAS. Our data suggest that blockade of the RAS is associated with increased 30-day in-hospital mortality. Hypertension could not be excluded as a possible confounding variable. An association between chronic blockade of the RAS and increased 30-day mortality was found. It is not known if stopping these medications prior to surgery would alter this finding. A careful evaluation of the risks and benefits of ACE inhibitors or ARA agents should be factored into the decision for their continuance up to the time of major surgery. More studies are needed to evaluate the mechanism of the drug interaction of agents that block the reninagiotensin system and anesthetic agents. The potential roles played by diabetes and medication exposures (especially diuretics) should also be considered in the design of future related studies.

Acknowledgements The authors sincerely thank the following individuals: Dr. Tom Einarson for his statistical advice; Dr. Patricia Houston for facilitating patient recruitment at the St. Michaels' Hospital study site, and Dr. Lynn Covney for her advice and contributions to the writing and revisions of the manuscript.

Financial support Department of Clinical Pharmacology, University of Toronto; Department of Anesthesia, Sunnybrook Hospital, Toronto, Ontario; Department of Anesthesia and Perioperative Medicine, University of Western Ontario.

Conflict of interest None declared. 


\section{References}

1. Bohm M. Angiotensin receptor blockers versus angiotensin-converting enzyme inhibitors: were do we stand now? Am J Cardiol 2007; 100(Suppl 1): S38-44.

2. Hernandez AF, Harrington RA. Comparative effectiveness of angiotensin-converting-enzyme inhibitors: is an ACE always an ace? CMAJ 2008; 178: 1316-9.

3. Fleisher LA, Beckman JA, Brown KA, et al. ACC/AHA 2007 guidelines on perioperative cardiovascular evaluation and care for noncardiac surgery: executive summary: a report of the American College of Cardiology/American Heart Association Task Force on Practice Guidelines (writing committee to revise the 2002 guidelines on Perioperative Cardiovascular Evaluation for Noncardiac Surgery) Anesth Analg 2008; 106: 685-712

4. Cittanova ML, Zubicki A, Savu C, et al. The chronic inhibition of angiotensin-converting enzyme impairs postoperative renal function. Anesth Analg 2001; 93: 1111-5.

5. Bertrand M, Godet G, Meersschaert K, Brun L, Salcedo E, Coriat $P$. Should the angiotensin II antagonists be discontinued before surgery? Anesth Analg 2001; 92: 26-30.

6. Colson P, Ryckwaert F, Coriat P. Renin angiotensin system antagonists and anesthesia. Anesth Analg 1999; 89: 1143-55.

7. Miller ED. The role of the renin-angiotensin-aldosterone system in circulatory control and in hypertension. Br J Anaesth 1981; 53: 711-8.

8. Miller ED Jr, Ackerly JA, Peach MJ. Blood pressure support during general anesthesia in a renin-dependent state in the rat. Anesthesiology 1978; 48: 404-8.

9. Kheterpal S, Khodaparast O, Shanks A, O'Reilly M, Tremper KK. Chronic angiotensin-converting enzyme inhibitor or angiotensin receptor blocker therapy combined with diuretic therapy is associated with increased episodes of hypotension in noncardiac surgery. J Cardiothorac Vasc Anesth 2008; 22: 180-6.

10. Rosenman DJ, McDonald FS, Ebbert JO, Erwin PJ, LaBella M, Montori VM. Clinical consequences of withholding versus administering renin-angiotensin-aldosterone system antagonists in the preoperative period. J Hosp Med 2008; 3: 319-25.

11. Feringa HHH, Bax JJ, Schouten O, Poldermans D. Protecting the heart with cardiac medication in patients with left ventricular dysfunction undergoing major noncardiac vascular surgery. Semin Cardiothorac Vasc Anesth 2006; 10: 25-31.

12. Miceli A, Capoun R, Fino $C$, et al. Effects of angiotensin-converting enzyme inhibitor therapy on clinical outcome in patients undergoing coronary bypass grafting. J Am Coll Cardiol 2009; 54: 1778-84.

13. Spinler SA, Nawarskas JJ, Boyce EB, Connors JE, Charland SL, Goldfarb $S$. Predictive performance of ten equations for estimating creatinine clearance in cardiac patients. Iohexol Cooperative Study Group. Ann Pharmacother 1998; 32: 1275-83.

14. Rothman KJ, Greenland S, Lash TL. Modern Epidemiology, $3^{\text {rd }}$ ed. New York: Lippincott Williams \& Wilkins Inc.; 2008: 287

15. Rubin $D B$. Estimating causal effects from large data sets using propensity scores. Ann Intern Med 1997; 127: 757-63.

16. Gwathmey TM, Shaltout HA, Pendergrass KD, et al. Nuclear angiotensin II-type 2 (AT2) receptors are functionally linked to nitric oxide production. Am J Physiol Renal Physiol 2009; 296: F1484-93.

17. Ponnuchamy B, Kahlil RA. Cellular mediators of renal vascular dysfunction in hypertension. Am J Physiol Regul Integr Comp Physiol 2009; 296: R1001-18.

18. Yu J, Ogawa K, Tokinaga $Y$, Iwahashi S, Hatano $Y$. The vascular relaxing effects of sevoflurane and isoflurane are more important in hypertensive than in normotensive rats. Can J Anesth 2004; 51: 979-85.
19. Ishikawa A, Ogawa K, Tokinanga Y, Uematsu N, Mizumoto K, Hatano $Y$. The mechanism behind the inhibitory effect of isoflurane on angiotensin II-induced vascular contraction is different from that of sevoflurane. Anesth Analg 2007; 105: 97-102.

20. Arnold DM, Molinaro G, Warkentin TE, et al. Hypotensive transfusion reaction can occur with blood products that are leukoreduced before storage. Transfusion 2004; 44: 1361-6.

21. Kurzencwyg D, Filion KB, Pilote L, et al. Cardiac medical therapy among patients undergoing abdominal aortic aneurysm repair. Ann Vasc Surg 2006; 20: 569-76.

22. Wolters $U$, Wolf T, Stutzer H, Schroder T. ASA classification and perioperative variables as predictors of postoperative outcome. $\mathrm{Br}$ J Anaesth 1996; 77: 217-22.

23. Godet $G$, Fleron $M H$, Vicaut $E$, et al. Risk factors for acute postoperative renal failure in thoracic or thoracoabdominal aortic surgery: a prospective study. Anest Analg 1997; 85: 1227-32.

24. Powell RJ, Roddy SP, Meier GH, et al. Effect of renal insufficiency on outcome following infrarenal aortic surgery. Am J Surg 1997; 17: 126-30.

25. Cohen JD, Singer P, Grunburg G, Grozovski E, Sulkes J, Zelikowski A. Outcome after elective infrarenal aortic aneurysm surgery. World J Surg 1998; 22: 278-82.

26. Eyraud D, Bertrand M, Fleron $M H$, et al. Risk factors for mortality in abdominal aortic surgery (French). Ann Fr Anesth Reanim 2000; 19: 452-8.

27. Bayly PJ, Matthews JN, Dobson PM, Price ML, Thomas DG. In-hospital mortality from abdominal aortic surgery in Great Britain and Ireland: Vascular Anesthesia Society Audit. Br J Surg 2001; 88: 687-92.

28. Alonso-Perez M, Segura $R$, Pita $S$, Cal L. Operative results and death preditors for nonruptured abdominal aortic aneurysms in the elderly. Ann Vasc Surg 2001; 15: 306-11.

29. Chen JC, Hildebrand HD, Salvian AJ, et al. Predictors of death in nonruptured and ruptured abdominal aortic aneurysms. J Vasc Surg 1996; 24: 614-20.

30. Bequemin JP, Chemla E, Chatellier G, Allaire E, Melliere D, Desgranges $P$. Peroperative factors influencing the outcome of elective abdominal aorta aneurysm repair. Eur J Vasc Endovasc Surg 2000; 20: 84-9.

31. Mangano DT, Layug EL, Wallace A, Tateo I. Effect of atenolol on mortality and cardiovascular morbidity after noncardiac surgery. Multicenter Study of Perioperative Ischemia Research Group. N Engl J Med 1996; 335: 1713-20.

32. Poldermans D, Boersma E, Bax JJ, et al. The effect of bisoprolol on perioperative mortality and myocardial infarction in high-risk patients undergoing vascular surgery. Dutch Echocardiographic Risk Evaluation Applying Stress Echocardiography Study Group. N Engl J Med 1999; 341: 1789-94.

33. POISE Study Group, Deveraeux PJ, Yang H, Guyatt G, et al. Effects of extended-release metoprolol succinate in patients undergoing non-cardiac surgery (POISE Trial): a randomised controlled trial. Lancet 2008; 371: 1839-47.

34. Lindenauer PK, Pekow P, Wang K, Mamidi DK, Gutierrez B, Benjamin EM. Perioperative beta-blocker therapy and mortality after major noncardiac surgery. N Engl J Med 2005; 353: 349-61.

35. Poldermans D, Bax JJ, Kertai MD, et al. Statins are associated with a reduced incidence of perioperative mortality in patients undergoing major noncardiac vascular surgery. Circulation 2003; 107: 1848-51.

36. Wijeysundera DN, Beattie WS. Calcium channel blockers for reducing cardiac morbidity after noncardiac surgery: a metaanalysis. Anesth Analg 2003; 97: 634-41. 